\title{
Surface and top-of-atmosphere radiative feedback kernels for CESM-CAM5
}

\author{
Angeline G. Pendergrass, Andrew Conley, and Francis M. Vitt \\ National Center for Atmospheric Research, Boulder, CO, 80305, USA \\ Correspondence: Angeline G. Pendergrass (apgrass@ucar.edu)
}

Received: 13 September 2017 - Discussion started: 16 October 2017

Revised: 9 January 2018 - Accepted: 11 January 2018 - Published: 21 February 2018

\begin{abstract}
Radiative kernels at the top of the atmosphere are useful for decomposing changes in atmospheric radiative fluxes due to feedbacks from atmosphere and surface temperature, water vapor, and surface albedo. Here we describe and validate radiative kernels calculated with the large-ensemble version of CAM5, CESM1.1.2, at the top of the atmosphere and the surface. Estimates of the radiative forcing from greenhouse gases and aerosols in RCP8.5 in the CESM large-ensemble simulations are also diagnosed. As an application, feedbacks are calculated for the CESM large ensemble. The kernels are freely available at https://doi.org/10.5065/D6F47MT6, and accompanying software can be downloaded from https://github.com/apendergrass/cam5-kernels.
\end{abstract}

\section{Introduction}

A radiative feedback kernel is the radiative response to a small perturbation in, for example, temperature or water vapor. Radiative feedback kernels for the top of the atmosphere (TOA) are useful for decomposing changes in atmospheric radiative fluxes due to feedbacks from atmosphere and surface temperature, water vapor, and surface albedo (Soden and Held, 2006). Radiative kernels at the surface or in the atmospheric column are useful for evaluating the radiative effect on precipitation (Pendergrass and Hartmann, 2014; Previdi, 2010).

Widely used TOA radiative kernels were calculated with the GFDL model (Soden and Held, 2006). Other kernels include those from CAM3 (Shell et al., 2008) and more recently from the MPI-ESM-LR model (Block and Mauritsen, 2013). The only publicly available model-based surface radiative kernels are from ECHAM5 (Previdi, 2010) and MPIESM-LR, which is a more recent version of the ECHAM model (discussed in Fläschner et al., 2016). Reanalysis-based kernels generated with ERA-Interim and RRTM are also available (Huang et al., 2017). Not all kernels have been validated to test the accuracy to which total radiative fluxes from a model simulation can be recovered with kernel calculations; examples that have been validated against model calculations of radiative flux due to doubling of carbon diox- ide include Shell et al. (2008), Block and Mauritsen (2013), and Huang et al. (2017).

Here we describe and validate radiative kernels calculated with CESM-CAM5 (Hurrell et al., 2013) for the top of the atmosphere and the surface. These radiative feedback kernels were calculated with CESM version 1.1.2, the same as that used for the 40-member CESM large ensemble (Kay et al., 2015). The TOA kernels are an update from CAM3 (Shell et al., 2008). We also include estimates of radiative forcing due to greenhouse gases and aerosols in RCP8.5 in the CESM large-ensemble simulations, which are necessary for calculating the cloud feedback using radiative kernels.

\section{Calculations}

In order to calculate the radiative feedback kernels, we make offline radiative transfer calculations following the methodology of Soden and Held (2006) with the Parallel Offline Radiative Transfer (PORT; Conley et al., 2013) code, updated for compatibility with CAM5 microphysics and RRTMG radiation (Iacono et al., 2008). We reintegrate the first member of the CESM large ensemble for 1 year to obtain the full instantaneous atmospheric model state, including temperature, mixing ratio, and clouds, to run offline radiative calculations, writing out instantaneous fields every $3 \mathrm{~h}$. All calculations 

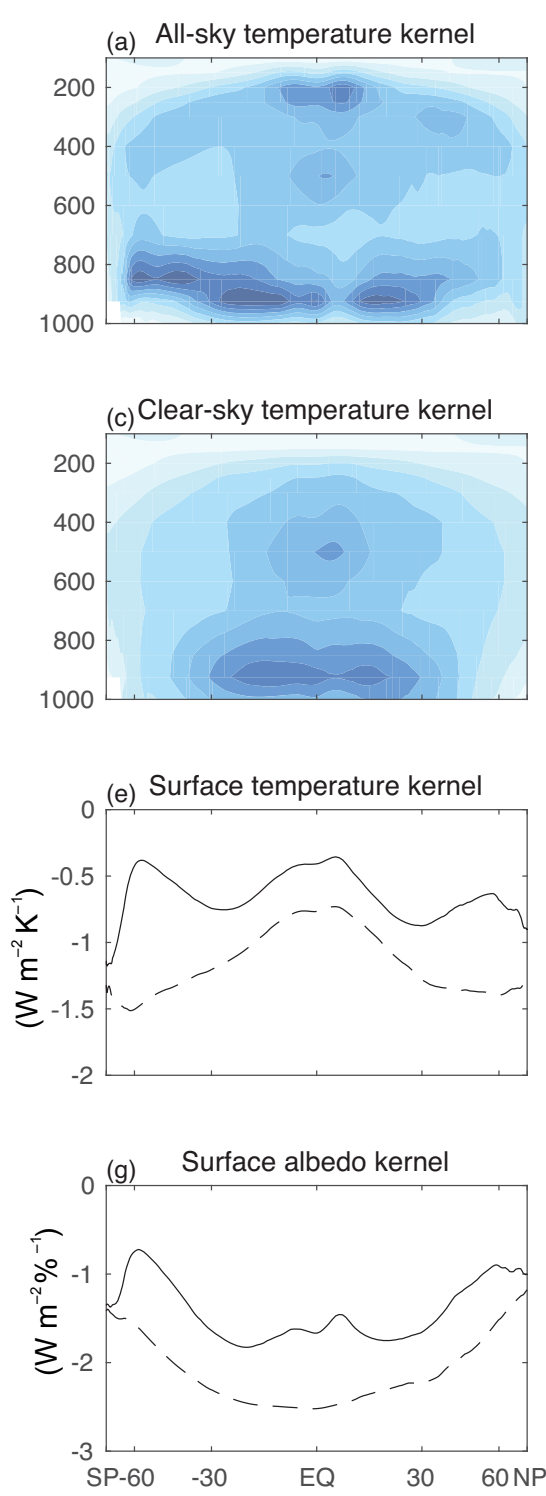
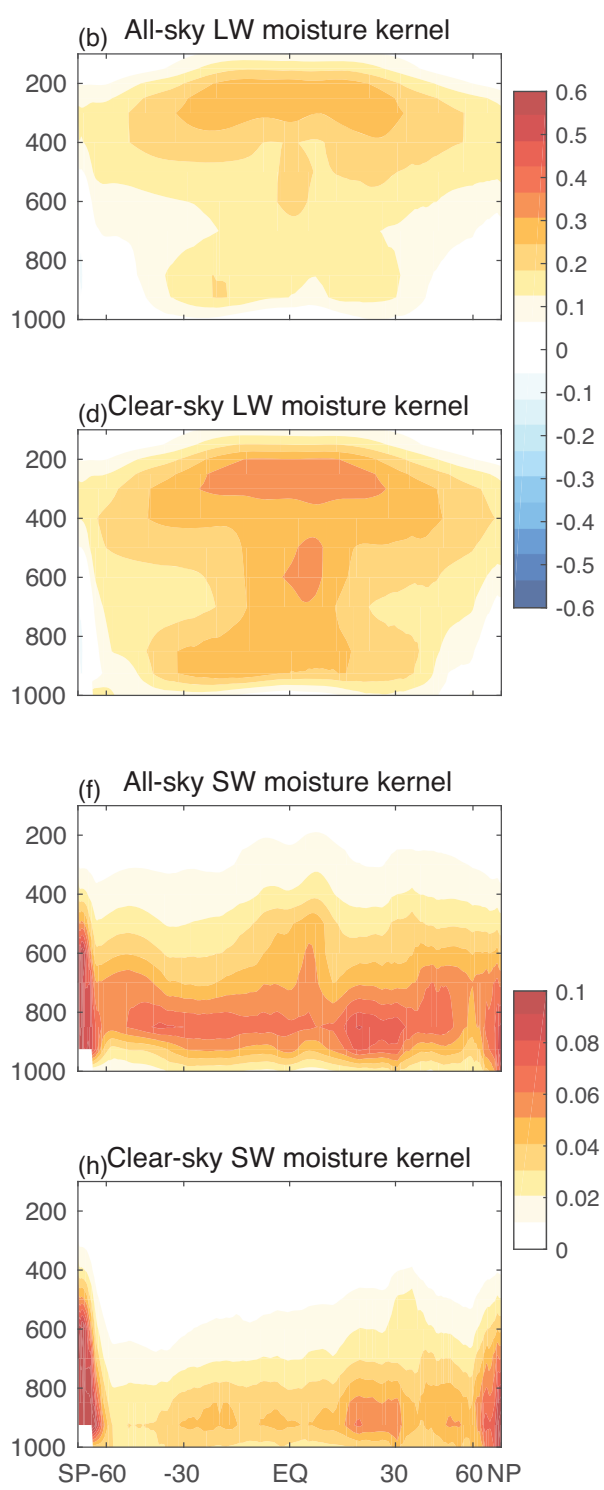

Figure 1. Top-of-atmosphere kernels from CESM1(CAM5). Zonal, annual-mean temperature, longwave moisture, and shortwave moisture kernels for all-sky and clear-sky. In panels (e) and (g) all-sky kernels are shown in solid lines and clear-sky kernels in dashed lines. The sign convention is positive downward.

were completed on NCAR's Yellowstone computer system (Computational and Information Systems Laboratory, 2012).

\subsection{Radiative kernels}

Together, all calculations consumed approximately 200000 core hours on NCAR's Yellowstone supercomputer. The limiting factor for throughput is the size of PORT input data: 3-hourly 3-D temperature, moisture, and cloud fields; about 7.5 TB of disk space is needed to run 1 month of 3-hourly PORT calculations for each vertical level of each kernel, with 63 global radiative transfer computations per kernel month (control, surface temperature, and albedo each require 1 ker- nel month, and atmospheric temperature and moisture each require 30). The kernel calculation is run for 1 year. The TOA radiative kernels are shown in Fig. 1, and surface kernels in Fig. 2. The atmospheric column kernel is the difference between these two kernels. The procedure to produce each kernel follows below. To create these plots, the kernels are regridded to standard CMIP5 pressure levels in the troposphere, including pressure weighting (a vertical regridding script is available at https://github.com/apendergrass/ cam5-kernels), and then the zonal and annual means are calculated. A description of the physical drivers of the changes in radiative fluxes is available from Ingram (2010) for the 
(a) All-sky temperature kernel
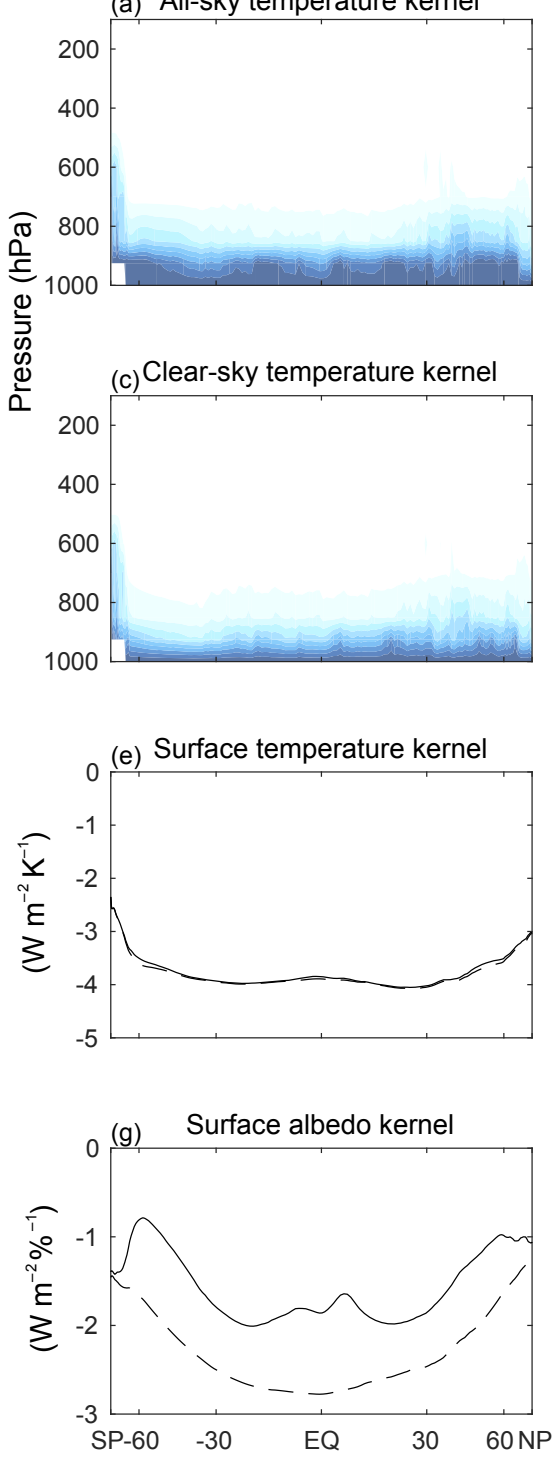

(b) All-sky LW moisture kernel

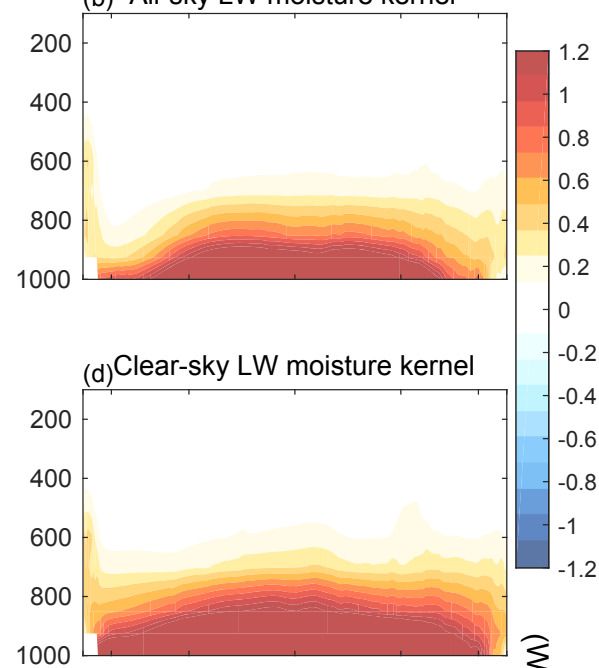

$3_{\substack{1 \\ N}}$
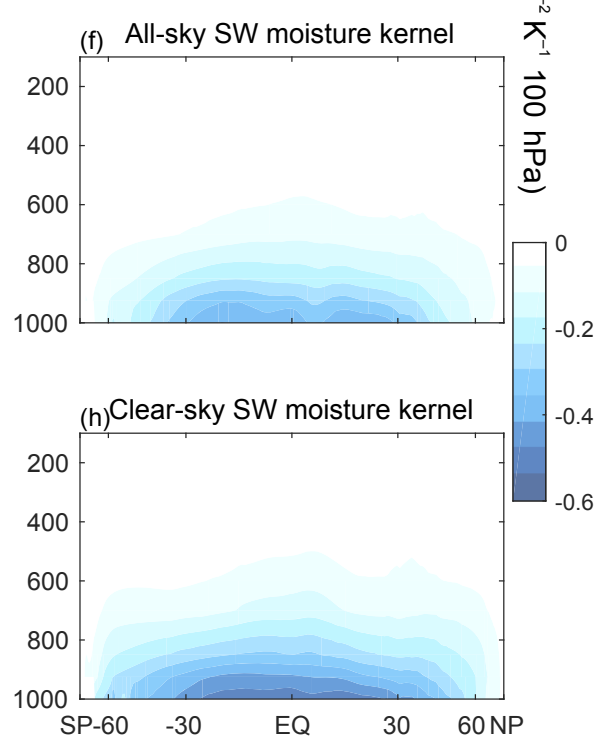

Figure 2. Surface kernels from CESM (CAM5). Zonal, annual-mean temperature, longwave moisture, and shortwave moisture kernels for all-sky and clear-sky cases. In panels (e) and (g) all-sky kernels are shown in solid lines and clear-sky kernels in dashed lines. The sign convention is positive downward.

TOA and Pendergrass and Hartmann (2014) for the atmospheric column.

\subsubsection{Atmospheric temperature kernel}

To calculate the atmosphere temperature kernel, we perturb the air temperature by $1 \mathrm{~K}$ in each hybrid sigma-pressure level at a time, at each grid cell for each 3-hourly instantaneous field. Then we calculate the monthly mean, and take the difference of the TOA and surface radiative fluxes from the control in response to each perturbation. PORT is adjusted so that the hygroscopic growth of aerosols is not affected by the modified temperatures and water vapor con- centrations. The calculations are carried out in CESM's hybrid sigma-pressure vertical coordinate and have units of $\mathrm{W} \mathrm{m}^{-2} \mathrm{~K}^{-1}$ level $^{-1}$. These hybrid sigma-pressure radiative feedback kernels can be interpolated onto standard CMIP pressure levels (see the description of example code in Sect. 5), as is done for display purposes here; the atmospheric temperature kernel is shown in Fig. 1a, c for the TOA and Fig. 2a, c for the surface.

\subsubsection{Surface temperature kernel}

In CESM, surface temperature enters radiative calculations indirectly via upwelling longwave flux at the surface. To cal- 
culate the surface contribution to the temperature kernel, we perturb upwelling surface longwave radiation by an amount consistent with $1 \mathrm{~K}$ warming at constant effective emissivity. The surface temperature kernels are shown in Figs. 1, 2e.

\subsubsection{Atmospheric moisture kernel}

The atmospheric moisture kernel is constructed by perturbing the mixing ratio on each hybrid sigma-pressure level by the amount that would result in constant relativehumidity moistening if there were a warming of $1 \mathrm{~K}$. The saturation mixing ratio is calculated for each $3 \mathrm{~h}$ instantaneous state using the mixhum_ptd function in NCL (UCAR/NCAR/CISL/TDD, 2015), which calculates saturation with respect to liquid water following List (1951). Code to closely approximate the perturbation with monthly-mean fields using this NCL calculation is provided (dq1k.ncl). As with the temperature kernel, the mixing ratio does not change for the purpose of aerosol radiative properties (hygroscopic growth is held invariant). The moisture kernel is shown in Figs. 1, 2b, d, f, h.

\subsubsection{Surface albedo kernel}

The surface albedo kernel is the change in radiative flux for a $1 \%$ change in surface albedo. The calculation is carried out by perturbing the direct and diffuse shortwave albedos, asdir and asdif, simultaneously by $1 \%$ each. The surface albedo kernel is shown in Figs. 1, 2g.

\subsection{Forcing}

To estimate the radiative forcing, we reintegrate CESM for the year 2096, writing out the fields needed for PORT calculations every $3 \mathrm{~h}$. The baseline for the forcing calculations is the same 2006 control as the kernel calculations. The greenhouse gas and aerosol forcing are shown in Fig. 3.

\subsubsection{Greenhouse gas forcing}

We use the greenhouse gas concentrations (carbon dioxide, methane, CFCs, $\mathrm{N}_{2} \mathrm{O}$, and ozone) from 2096 with the tropospheric temperature, mixing ratio, and other radiatively relevant fields from 2006. To account for stratospheric adjustment, we use the 2096 stratospheric temperature and water vapor mixing ratio in the calculation. The tropopause is defined as $100 \mathrm{hPa}$ at the equator and $300 \mathrm{hPa}$ at the poles and varies by cosine of latitude in between, following Soden and Held (2006). The resulting estimate approximates the radiative forcing following the definition of Myhre et al. (2013), though it includes adjustment of water vapor as well as temperature in the stratosphere.

\subsubsection{Aerosol forcing}

To calculate the aerosol forcing, we apply black carbon, sulfate, secondary organic aerosol, primary organic matter, dust, sea salt, and aerosol temperature and mixing ratio from 2096 with temperature, mixing ratio, greenhouse gas, and all other fields from 2006, with no adjustments to the stratosphere. The resulting estimate is the instantaneous radiative forcing.

\section{Validation}

Radiative kernels enable a useful but approximate decomposition of the contributions to changes in radiative fluxes. Application of radiative kernels assumes that changes in radiative fluxes are linear with respect to changes in constituents, and that the response to changes in temperature and moisture at different vertical levels are independent. These assumptions are not exactly met, even for clear-sky fluxes (Feldl and Roe, 2013). We undertake a validation exercise focused on quantifying the errors associated with these kernels compared to the climate-model-simulated changes in radiative flux they are targeted at.

First, we quantify the error of the kernel-estimated change in radiative flux of the ensemble member from which the kernels are computed. The changes in radiative flux associated with the temperature, water vapor, and albedo feedbacks are calculated using the changes in monthly-mean model fields, and then the change in radiative forcing is added. The globalmean modeled and kernel-estimated changes in radiative flux as well as the error in global mean and global-mean absolute error are documented in Table 1. For the global-mean absolute error, the change in annual-mean radiative fluxes is calculated, then the absolute value of the error for each ensemble member is calculated at each grid point, and finally the global mean of this quantity is calculated. These error estimates include errors due to sampling every $3 \mathrm{~h}$ (instead of at each model time step) and due to the nonlinearity neglected by the kernel method. While we only document the changes in clear-sky radiative flux response in Table 1, the errors in all-sky radiative fluxes are exactly the same when cloud feedback is estimated using the adjusted cloud radiative effect method described in Soden et al. (2008). Errors in global-mean radiative flux change range from 0.1 to $0.8 \mathrm{Wm}^{-2}$, while global-mean absolute errors range from 0.7 to $1.4 \mathrm{Wm}^{-2}$. Errors in shortwave (SW) fluxes are smaller than for longwave (LW) fluxes.

Because the kernel calculation is computationally intensive, it is based on just 1 year. Next, we quantify the error of the kernel-estimated radiative fluxes compared to members 2-40 of the CESM1 large ensemble. This error estimate includes the effect of our choice of a single year, as well as nonlinearity and 3-hourly sampling. The global-mean error for each ensemble member is shown in Fig. 4. The globalmean absolute errors are not especially larger for the ensemble mean than for member 1 . The change in TOA LW fluxes 


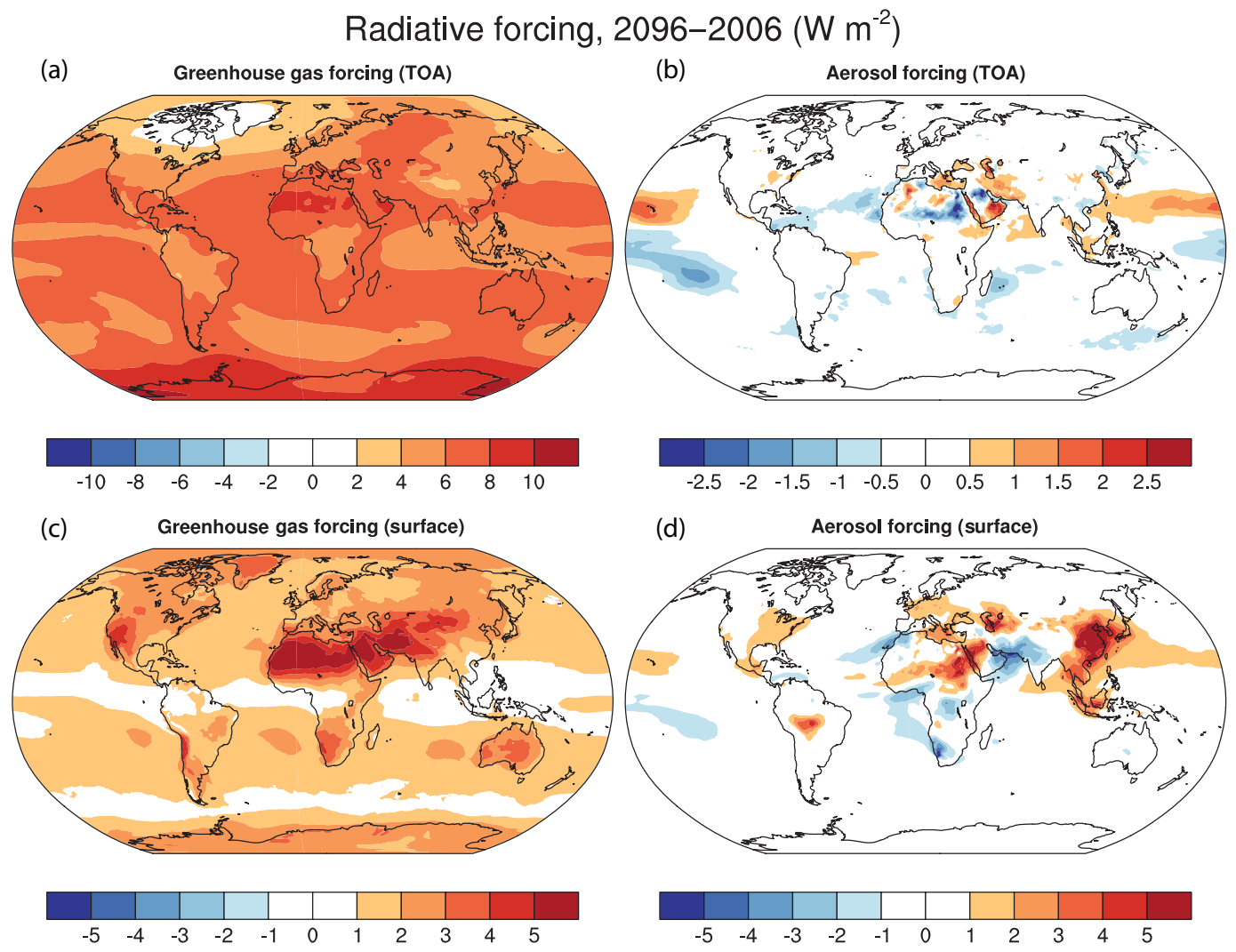

Figure 3. Radiative forcing. Net ( $\mathrm{LW}+\mathrm{SW}$ ) radiative forcing under the RCP8.5 scenario diagnosed from CESM (CAM5) for greenhouse gases $(\mathbf{a}, \mathbf{c})$ and the direct aerosol radiative forcing $(\mathbf{b}, \mathbf{d})$ at the TOA $(\mathbf{a}, \mathbf{b})$ and surface $(\mathbf{c}, \mathbf{d})$.

Table 1. Top-of-atmosphere (TOA) and surface clear-sky radiative responses $\left(\mathrm{Wm}^{-2}\right)$ for 2096-2006 from CESM1 large-ensemble member 1 (from which the kernels are derived) and the estimated radiative fluxes using the kernels and radiative forcing.

\begin{tabular}{lrr|rr}
\hline & \multicolumn{2}{c}{ TOA } & \multicolumn{2}{c}{ Surface } \\
\cline { 2 - 5 } & LW & SW & LW & SW \\
\hline Member 1 response & -1.3 & 3.1 & 9.5 & -1.4 \\
Kernel estimate & -0.7 & 3.4 & 10.3 & -1.2 \\
Error of global mean & 0.6 & 0.4 & 0.8 & 0.1 \\
Global-mean abs. error & 1.4 & 0.7 & 1.4 & 1.3 \\
\hline
\end{tabular}

has more interannual variability than TOA SW and surface fluxes. The error of global-mean change in radiative flux is similar to member 1 for SW fluxes but larger for LW fluxes $\left(0.9 \mathrm{Wm}^{-2}\right.$ at both the surface and TOA; not shown). The spatial pattern of ensemble-mean error is shown in Fig. 5. The LW errors, particularly for the surface, are large in the tropics. For the TOA, there are also substantial errors at high latitudes of both hemispheres. The largest errors in the SW are associated with sea-ice edges, the movement of which is not captured well by the kernel method. There are also re-

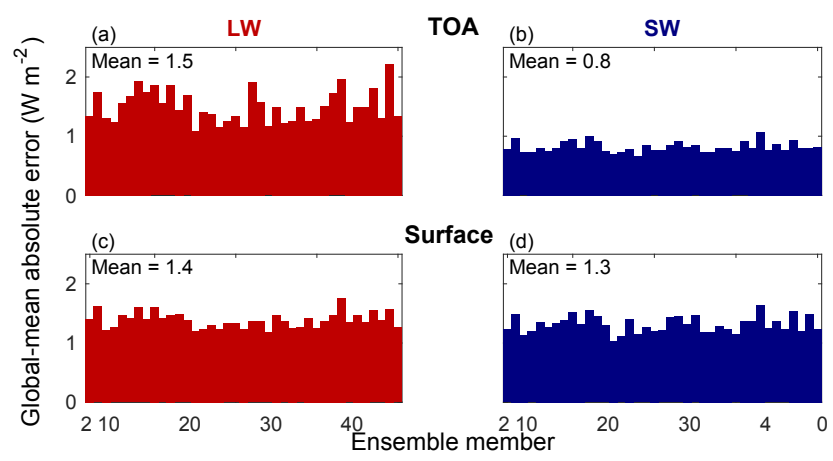

Figure 4. Validation across ensemble members. Global-mean absolute error of kernel-estimated clear-sky radiative flux change from 2006 to 2096 for members 2-40 of the CESM1 large ensemble for LW $(\mathbf{a}, \mathbf{c})$ and SW $(\mathbf{b}, \mathbf{d})$ fluxes at the TOA $(\mathbf{a}, \mathbf{b})$ and surface $(\mathbf{c}, \mathbf{d})$.

gions of large error associated with tropical clouds, and at the TOA, there is a bias over Antarctica.

In applications that make use of experiments from models other than CESM (CAM5), errors will also arise due to differences in radiative transfer codes between models (e.g., DeAngelis et al., 2015; Soden et al., 2008); we do not quantify these errors explicitly here, but we do compare feedback 


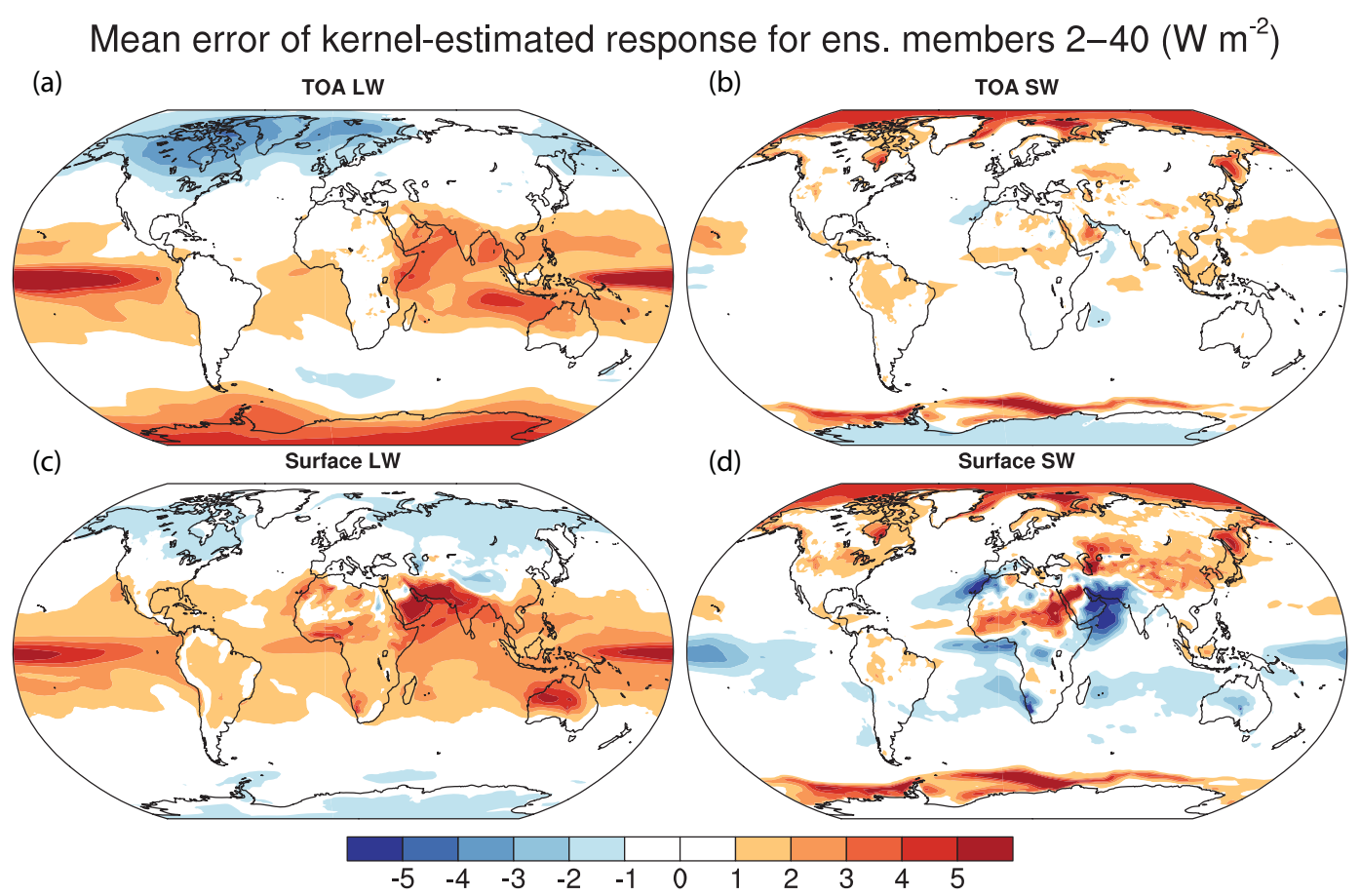

Figure 5. Spatial pattern of error. Mean error of kernel-estimated radiative flux change from 2006 to 2096 for members $2-40$ of the CESM1 large ensemble for LW (a, c) and SW (b, d) fluxes at the TOA $(\mathbf{a}, \mathbf{b})$ and surface $(\mathbf{c}, \mathbf{d})$.

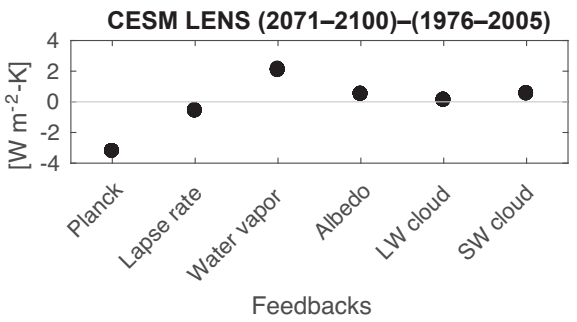

Figure 6. CESM large-ensemble kernels. Feedback calculation for the CESM 40-member large ensemble using the TOA kernels.

decompositions made with other radiative kernels from the literature in Sect. 4.

\section{Application}

Next we show a sample application of the kernels to the CESM large-ensemble simulations. In order to apply the kernels, one needs monthly changes in temperature, mixing ratio, and surface albedo as well as long-term mean water vapor mixing ratios to calculate the logarithm of water vapor change (Soden et al., 2008). To calculate the cloud feedback, change in cloud radiative effect is also required. Then, the monthly-resolved kernels and changes in atmospheric state are convolved to obtain the changes in radiative flux components. Example code for applying the kernels is available at https://github.com/apendergrass/cam5-kernels.
Table 2. Comparison of TOA radiative feedbacks. TOA radiative feedbacks $\left(\mathrm{Wm}^{-2} \mathrm{~K}^{-1}\right)$ averaged over 40 CESM large-ensemble simulations diagnosed with CAM5 radiative kernels, compared against those from CMIP3 model simulations diagnosed with three different kernels as reported by Soden et al. (2008), and MPI-ESMLR control state kernels and years 21-150 of abrupt carbon dioxide quadrupling simulations from the same model (Block and Mauritsen, 2013).

\begin{tabular}{lrrr}
\hline Feedback & Here & $\begin{array}{r}\text { Soden et al. } \\
(2008)\end{array}$ & $\begin{array}{r}\text { Block and } \\
\text { Mauritsen }(2013)\end{array}$ \\
\hline Planck & -3.2 & -3.1 or -3.2 & -3.19 \\
Lapse rate & -0.58 & -1 & -0.64 \\
Water vapor & 2.1 & 1.9 & 1.79 \\
Albedo & 0.51 & 0.3 & 0.48 \\
Cloud & 0.66 & 0.77 & 0.62 \\
\hline
\end{tabular}

We apply the radiative kernels to the CESM largeensemble integrations to diagnose the top-of-atmosphere radiative feedbacks. The changes in surface and tropospheric temperature, water vapor mixing ratio, surface albedo, and cloud radiative effect are calculated from 30-year averages for each month from each ensemble member, 1976-2005 and 2071-2100. The cloud feedback calculation follows Soden et al. (2008). The global, annual-mean change in radiative flux for each feedback is calculated and then normalized by the change in global-mean surface temperature for each ensem- 
Table 3. Data files comprising the dataset.

\begin{tabular}{lrll}
\hline File name & Size & Units & Description \\
\hline alb.kernel.nc & $20 \mathrm{MB}$ & $\mathrm{W} \mathrm{m}^{-2} \%^{-1}$ & Albedo kernel \\
ts.kernel.nc & $20 \mathrm{MB}$ & $\mathrm{W} \mathrm{m}^{-2} \mathrm{~K}^{-1}$ & Surface temperature kernel \\
t.kernel.nc & $608 \mathrm{MB}$ & $\mathrm{W} \mathrm{m}^{-2} \mathrm{~K}^{-1}$ level $^{-1}$ & Air temperature kernel \\
q.kernel.nc & $1.2 \mathrm{~GB}$ & $\mathrm{~W} \mathrm{~m}^{-2} \mathrm{~K}^{-1}$ level $^{-1}$ & Moisture kernel \\
ghg.forcing.nc & $41 \mathrm{MB}$ & $\mathrm{W} \mathrm{m}^{-2}$ & Greenhouse gas forcing \\
aerosol.forcing.nc & $41 \mathrm{MB}$ & $\mathrm{W} \mathrm{m}^{-2}$ & Aerosol forcing \\
PS.nc & $5.1 \mathrm{MB}$ & $\mathrm{Pa}$ & Surface pressure \\
\hline
\end{tabular}

ble member; then, the ensemble average is calculated. Results are shown in Table 2 and Fig. 6.

Table 2 shows a comparison between feedback values calculated here and those diagnosed with other kernels and model simulations. Soden et al. (2008) report radiative feedbacks from 14 CMIP3 model simulations using three different sets of radiative kernels from CAM3, GFDL, and CAWCR. The Planck response agrees closely. Water vapor and albedo feedbacks are both within $0.2 \mathrm{Wm}^{-2} \mathrm{~K}^{-1}$. The cloud feedback differs by only $0.1 \mathrm{Wm}^{-2} \mathrm{~K}^{-1}$, despite the fact that Soden et al. (2008) do not account for aerosol radiative forcing. The only notable disagreement is in the lapse rate feedback by $0.4 \mathrm{Wm}^{-2} \mathrm{~K}^{-1}$. Because the Planck feedback agrees closely between the two calculations, the difference is probably not due to the temperature kernel. Instead, it may be caused by differing upper tropospheric temperature amplification between the CMIP3 and CESM largeensemble simulations or due to underlying differences in the radiation codes. Block and Mauritsen (2013) report radiative feedbacks using MPI-ESM-LR kernels applied to abrupt carbon dioxide quadrupling experiments with the same model (they compare kernels calculated from different base states and apply them to short transient response and more developed long-timescale response; we compare with their control base-state kernels applied to long-timescale climate response because this is most similar to our application). There is remarkably close agreement for all feedbacks, excepting only the water vapor feedback. This could arise from the kernels or from the change in water vapor in the simulations.

\section{Code and data availability}

The provided dataset includes the four monthly-mean radiative kernels; atmospheric temperature, surface temperature, water vapor, and surface albedo; and radiative forcing from greenhouse gases and aerosols. Data are provided on the CESM hybrid-sigma grid for comparison with CESM simulations. The dataset includes net all-sky and clear-sky radiative fluxes at both the top of the atmosphere and surface. The sign convention is the same as CESM's: shortwave fluxes are positive downward, and longwave fluxes are positive upward. Sample temperature, moisture, surface radiative fluxes, and surface pressure are also included, as well as sample code to facilitate use of the kernels.

The data and code to calculate TOA temperature, water vapor, and albedo feedbacks are available for immediate download at https://zenodo.org/record/997902 (though without directory structure) and through ESGF at https://www.earthsystemgrid.org/dataset/ucar.cgd.ccsm4. cam5-kernels.html (Pendergrass, 2017a). The files included are listed in Table 3. Additional software tools - to regrid the kernels to pressure levels (including CMIP standard levels), and calculate TOA Planck, lapse rate, and cloud feedbacks are available at https://doi.org/10.5281/zenodo.997899 (Pendergrass, 2017b).

\section{Path forward}

There is room to improve the accuracy of these and other radiative kernels. Future work could explore new sampling strategies to capture both the diurnal cycle and interannual variability (which would be particularly important for regional applications), directly compare different kernels, and quantify the radiative forcing in climate simulations.

Competing interests. The authors declare that they have no conflict of interest.

Acknowledgements. William Frey and Ryan Kramer provided valuable feedback on validating the kernels and testing and debugging code. Paulo Ceppi provided valuable feedback on the discussion version of the paper as well as the associated software. Angeline G. Pendergrass was supported by an NCAR Advanced Studies Postdoctoral Research Fellowship and by the Regional and Global Climate Modeling Program (RGCM) of the US Department of Energy's Office of Science (BER), cooperative agreement DEFC02-97ER62402. NCAR is sponsored by the National Science Foundation. Computing resources were provided by the Climate Simulation Laboratory at NCAR's Computational and Information Systems Laboratory (CISL), sponsored by the National Science Foundation and other agencies. 
Edited by: David Carlson

Reviewed by: two anonymous referees

\section{References}

Block, K. and Mauritsen, T.: Forcing and feedback in the MPI-ESM-LR coupled model under abruptly quadrupled $\mathrm{CO}_{2}$, J. Adv. Model. Earth Syst., 5, 676-691, https://doi.org/10.1002/jame.20041, 2013.

Computational and Information Systems Laboratory: Yellowstone: IBM iDataPlex System (NCAR Community Computing), available at: http://n2t.net/ark:/85065/d7wd3xhc, 2012.

Conley, A. J., Lamarque, J.-F., Vitt, F., Collins, W. D., and Kiehl, J.: PORT, a CESM tool for the diagnosis of radiative forcing, Geosci. Model Dev., 6, 469-476, https://doi.org/10.5194/gmd-6469-2013, 2013.

DeAngelis, A. M., Qu, X., Zelinka, M. D., and Hall, A.: An observational radiative constraint on hydrologic cycle intensification, Nature, 528, 249-53, https://doi.org/10.1038/nature15770, 2015.

Feldl, N. and Roe, G. H.: The nonlinear and nonlocal nature of climate feedbacks, J. Climate, 26, 8289-8304, https://doi.org/10.1175/JCLI-D-12-00631.1, 2013.

Fläschner, D., Mauritsen, T., and Stevens, B.: Understanding the intermodel spread in global-mean hydrological sensitivity, J. Climate, 29, 801-817, https://doi.org/10.1175/JCLI-D-15-0351.1, 2016.

Huang, Y., Xia, Y., and Tan, X.: On the pattern of $\mathrm{CO}_{2}$ radiative forcing and poleward energy transport, J. Geophys. Res.-Atmos., 122,, 10578-10593, https://doi.org/10.1002/2017JD027221, 2017.

Hurrell, J. W., Holland, M. M., Gent, P. R., Ghan, S., Kay, J. E., Kushner, P. J., Lamarque, J. F., Large, W. G., Lawrence, D., Lindsay, K., Lipscomb, W. H., Long, M. C., Mahowald, N., Marsh, D. R., Neale, R. B., Rasch, P., Vavrus, S., Vertenstein, M., Bader, D., Collins, W. D., Hack, J. J., Kiehl, J., and Marshall, S.: The Community Earth System Model: A framework for collaborative research, B. Am. Meteorol. Soc., 94, 1339-1360, https://doi.org/10.1175/BAMS-D-12-00121.1, 2013.

Iacono, M. J., Delamere, J. S., Mlawer, E. J., Shephard, M. W., Clough, S. A., and Collins, W. D.: Radiative forcing by long-lived greenhouse gases: Calculations with the AER radiative transfer models, J. Geophys. Res.-Atmos., 113, 2-9, https://doi.org/10.1029/2008JD009944, 2008.

Ingram, W.: A very simple model for the water vapour feedback on climate change, Q. J. Roy. Meteorol. Soc., 136, 30-40, https://doi.org/10.1002/qj.546, 2010.
Kay, J. E., Deser, C., Phillips, A., Mai, A., Hannay, C., Strand, G., Arblaster, J. M., Bates, S. C., Danabasoglu, G., Edwards, J., Holland, M., Kushner, P., Lamarque, J. F., Lawrence, D., Lindsay, K., Middleton, A., Munoz, E., Neale, R., Oleson, K., Polvani, L., and Vertenstein, M.: The Community Earth System Model (CESM) large ensemble project?: A community resource for studying climate change in the presence of internal climate variability, B. Am. Meteorol. Soc., 96, 1333-1349, https://doi.org/10.1175/BAMS-D-13-00255.1, 2015.

List, R. J. (Ed.): Smithsonian meteorological tables, 6th edn., The Smithsonian Institution, Washington, 1951.

Myhre, G., Shindell, D., Bréon, F.-M., Collins, W., Fuglestvedt, J., Huang, J., Koch, D., Lamarque, J.-F., Lee, D., Mendoza, B., Nakajima, T., Robock, A., Stephens, G., Takemura, T., and Zhang, H.: Anthropogenic and Natural Radiative Forcing, in Climate Change 2013: The Physical Science Basis. Contribution of Working Group I to the Fifth Assessment Report of the Intergovernmental Panel on Climate Change, edited by: Stocker, T. F., Qin, D., Plattner, G.-K., Tignor, M., Allen, S. K., Boschung, J., Nauels, A., Xia, Y., Bex, V., and Midgley, P. M., Cambridge University Press, Cambridge, United Kingdom and New York, NY, USA, 2013.

Pendergrass, A. G.: CAM5 Radiative Kernels, UCAR/NCAR Earth Syst. Grid, https://doi.org/10.5065/D6F47MT6, 2017a.

Pendergrass, A. G.: CESM CAM5 Kernel Software, Zenodo, https://doi.org/10.5281/zenodo.997899, 2017 b.

Pendergrass, A. G. and Hartmann, D. L.: The atmospheric energy constraint on global-mean precipitation change, J. Climate, 27, 757-768, https://doi.org/10.1175/JCLI-D-13-00163.1, 2014.

Previdi, M.: Radiative feedbacks on global precipitation, Environ. Res. Lett., 5, 25211, https://doi.org/10.1088/17489326/5/2/025211, 2010.

Shell, K. M., Kiehl, J. T., and Shields, C. A.: Using the radiative kernel technique to calculate climate feedbacks in NCAR's Community Atmospheric Model, J. Climate, 21, 2269-2282, https://doi.org/10.1175/2007JCLI2044.1, 2008.

Soden, B. J. and Held, I. M.: An Assessment of Climate Feedbacks in Coupled Ocean - Atmosphere Models, J. Climate, 19, 3354 3360, https://doi.org/10.1175/JCLI9028.1, 2006.

Soden, B. J., Held, I. M., Colman, R. C., Shell, K. M., Kiehl, J. T., and Shields, C. A.: Quantifying climate feedbacks using radiative kernels, J. Climate, 21, 3504-3520, https://doi.org/10.1175/2007JCLI2110.1, 2008.

UCAR/NCAR/CISL/TDD: The NCAR Command Language (NCL), Version 6.3.0, https://doi.org/10.5065/D6WD3XH5, 2015. 